\title{
Enhancing Theory-of-Mind Discourse among Deaf Parents of Children with Hearing Loss
}

\author{
Margalit Ziv ${ }^{1,2}$, Irit Meir ${ }^{3}$ \& Lucy Malky ${ }^{4}$ \\ ${ }^{1}$ Early Childhood Department, AlQasemi Academic College of education, Baka-Elgarbiya, Israel \\ ${ }^{2}$ School of education, Tel Aviv University, Israel \\ ${ }^{3}$ Department of Hebrew Language \& Department of Communication Disorders, University of Haifa, Haifa, Israel \\ ${ }^{4}$ MICHA Multidisciplinary Center for Infants, Toddlers and Preschool Children with Hearing Impairment, Tel Aviv \\ Correspondence: Irit Meir, Dept. of Hebrew Language, University of Haifa, Haifa 31905, Israel. Tel: \\ 972-4-828-8104. E-mail: imeir@univ.haifa.ac.il
}

Received: July 2, 2013 Accepted: July 18, 2013 Online Published: August 6, 2013

doi:10.11114/jets.v1i2.169 URL: http://dx.doi.org/10.11114/jets.v1i2.169

\begin{abstract}
Children with hearing loss often have difficulties in the socio-emotional domain that can be attributed to a significant delay in the development of theory of mind (ToM). The current article describes a workshop aimed at enhancing deaf parents' awareness of the importance of ToM development and enriching parent-child conversations with developmentally appropriate mental state contents. Eight deaf mothers from mid- low SES background participated in six sessions and were guided to enrich their mental discourse while naturally interacting with their deaf children. The mothers' use of mental terms was assessed at the beginning and end of the program. Following their participation in the workshop, mothers used more mental terms when interacting with their children, explained more elaborately mental motives underlying people's behavior and described their children's personality by referring more frequently to their social likes and dislikes. We conclude that parental guidance that addresses parents' interests and needs can assist in enriching their mental discourse and mediation when interacting with their children. As parents are major agents in enhancing development of theory of mind, the reported change may have long-lasting effects on their children.
\end{abstract}

Keywords: theory-of-mind, hearing loss, deaf, parents, toddlers, mental discourse

\section{Introduction}

Children with hearing loss often have difficulties in the social domain that prevail in their interactions with peers and adults (Calderon and Greenberg, 2003). These difficulties may be at least partly attributed to a delay in the development of theory of mind (ToM) (Peterson \& Siegal, 2000). While the development of ToM matures with age, various factors have been singled out as contributing and enhancing this development. Among these is parental input. Previous studies have shown that parental input has an important effect on the child's mental discourse (e.g., Adrián, Clemente, \& Villanueva, 2007). Therefore, an important way of enhancing ToM development in at-risk children is promoting parents' mental discourse with children. The current article describes a workshop whose aim was to enhance deaf parents' references to mental states while conversing with their deaf children. The workshop consisted of six meetings, conducted by the children's day-care teacher, in which deaf parents participated. Preliminary evaluation of the program is presented, in order to highlight its potential in enriching parent-child discourse and in promoting deaf toddlers' ToM foundations. Hopefully, the description of the program will deepen the recognition of researchers, professionals and parents regarding ecologically valid ways of promoting socio-cognitive abilities in children with hearing loss, and will serve as one example, followed by many others, of successful ways to do so.

\subsection{The Development of Theory of Mind (ToM) in Typically Developing Hearing Children}

ToM is a central component of human social cognition and refers to the ability to understand mental states upon which human behavior and social interactions are based. The primary mental states include beliefs, intents, desires and emotions. By understanding these motives, human beings are able to explain, predict and attribute significance to their own behavior and to that of others (Flavell \& Miller, 2000). A significant milestone in the development of 
ToM is the ability to understand false beliefs. Using a standard experimental task that requires children to predict what a protagonist will do or say when in the grips of a false belief regarding the location of an object (Wimmer \& Perner, 1983), studies indicate that most typically developing hearing children succeed in the tasks towards the age of 5 years (Wellman, Cross, \& Watson, 2001; Liu, Wellman, Tardif \& Sabbagh, 2008).

Children gradually construct the foundations for a mature ToM during the first three years of life. An initial understanding of covert intentions emerges already during the first year (Tomasello, Carpenter, Call, Behne, \& Moll, 2005). During the second year toddlers begin to understand important aspects of people's desires and emotions. They can recognize that there may be a difference between what they want and what another person wants (Repaccoli \& Gopnik, 1997; Peterson, Wellman \& Slaughter, 2012) and understand that fulfilled desires make one feel happy whereas unfulfilled desires can cause sadness or anger (Wellman, Phillips \& Rodriguez, 2000). In addition, two-year-olds begin to understand feelings of others, and to show empathy for children or adults showing signs of distress (Zahn-Waxler, Radke-Yarrow \& Wagner, 1992). Toddlers also start talking about what people want, like and feel (Astington \& Barriault, 2001) and gradually become partners in conversations about mental motives that underlie people's behavior (Harris, 2005).

\subsection{Development of ToM among Deaf Children}

Peterson and Siegal (1995) were the first to investigate ToM development among children with hearing loss by examining the understanding of false beliefs among children aged eight to thirteen. Most of the participants in their study and in later studies were deaf children with hearing parents who communicated using oral language or who had begun signing only at the beginning of elementary school. The studies showed that these children exhibit a major delay in their understanding of false beliefs, arriving at such understanding only between age eight and ten (Schick, deVilliers, deVilliers, \& Hoffmeister, 2007; Woolfe, Want, \& Siegal, 2002). Moreover, in social interactions during their years in school, they have difficulties relating to the points of view of others (Terwogt \& Rieffe, 2004).

Recently, Peterson and colleagues conducted comprehensive studies to explore deaf children's ability to understand a variety of situations in which the mental state of one character differed from that of another (Peterson \& Wellman, 2009; Peterson, Wellman, \& Liu, 2005; Peterson, Wellman \& Slaughter, 2012). Results reveal that orally-communicating and late-signing children are delayed not just on standard false-belief tasks but in understanding mental states in general. It has been suggested that the reason for the difficulties in understanding ToM exhibited by these children is related to their limited participation in high quality social interactions involving mental discourse, in their family or educational setting (Jeanes, Nienhuys, \& Rickards, 2000; Macaulay \& Ford, 2006; Preisler, Tvingstedt, \& Ahlstrom, 2002).

Recent studies on ToM among children with unilateral cochlear implants revealed inconsistent findings. Peterson (2004) found that implanted children ages 4-12 years demonstrated a 3-5-year delay in acquiring ToM, whereas other studies (Peters, Remmel, \& Richards, 2009; Remmel \& Peters, 2008) found that implanted children ages 3-12 years exhibited only a small delay. Furthermore, some children in the two latter studies showed no delay at all compared to hearing children, both with respect to ToM and with respect to their linguistic ability. The researchers concluded that implants assist in the development of spoken language, including mental and emotional terms, and consequently also render an impact on development of ToM.

In contrast to deaf children with hearing parents who have difficulty attributing mental states to people, deaf children whose parents are also deaf and who communicate with them using sign language from infancy do not exhibit difficulties in ToM development (Courtin, 2000; Courtin \& Melot, 2005; De Villers, 2006; Schick et al., 2007). The intact ToM among these children can be attributed first and foremost to their early and normal exposure to mental states through their natural and fertile communication in sign language, which is their mother tongue (Meir, 2007). In addition, most of the signing children who participated in ToM studies came from a high socioeconomic background marked by prolific mental discourse, as in hearing families from similar backgrounds.

\subsection{The Contribution of Parental Mediation to Children's ToM Development}

Studies highlight the important role of parents as central communicative and mediatory figures for young children. Natural interactions between mothers and children aged three to five, abundant with mental terms, e.g. want and think, encourage early development of mental understanding (Adrián, Clemente, Villanueva \& Rieffe, 2005; Adrián et. Al, 2007; Bernard \& Deleau, 2007; Ruffman, Slade \& Crowe, 2002). Such discourse encourages discussions of emotions and desires that underlie people's behavior (Curenton \& Craig, 2011; Taumoepeau \& Ruffman, 2008). Other studies have stressed the importance of exposing children to utterances whose syntactic structure consists of a mental verb complemented by a subordinate clause, as in "He thought that you wanted the doll." Such utterances emphasize the distinction between mental states and reality, and are argued to be central to the understanding of different points of view (Bernard \& Deleau, 2007; De Villiers, 2006). 
In a longitudinal study, Meins examined mothers' reference to mental states when interacting with their children from infancy to age five (Meins et al., 2003). Children whose mothers had referred to their mental states when they were six months old (e.g, "I see you are excited") and to mental aspects in their personalities at age three (e.g., "She senses what other people feel") exhibited better understanding of false beliefs and feelings of others at age five. The researchers stressed the importance of parental awareness of children's mental characteristics at the earliest stages of development.

Peterson and Slaughter (2003) designed a structured questionnaire for examining how parents relate to mental states in daily life. The questionnaire presented 12 situations and dilemmas in a variety of daily contexts together with four response options: two mental responses and two that were not. For each situation, parents were asked to select what they considered the most suitable option. The situations included, for example, an unwelcome neighbor dropping in for a visit and preparing a surprise birthday party for father. The findings pointed to a significant relation between the mother's choice of a detailed mental response and the child's level of theory of mind. The study reinforced findings of previous research, indicating that parental intervention in mental constructs is important in promoting cognitive-social development among preschool children.

When looking into the characterization of discourse between parents and their deaf children, the issue that immediately arises is that of the mode of communication. Most deaf children (more than $90 \%$ ) are born to hearing parents (Mitchell \& Karchmer, 2004). Hearing parents may decide to learn to sign and use a sign language or a communication system augmented by signing with their children. However, they need to acquire signing skills, and some parents may be better at that than others. Other hearing parents may decide not to sign and use only the spoken language with their children. In such cases the communication systems used for parents-child discourse is not fully accessible to the child. In both scenarios, there are communication difficulties, and these may have an effect on the quality and quantity of the parent-child discourse.

A few studies examined the mental discourse of hearing parents with their deaf children and found a limited number of mental-state references. Lundy (2002) examined the relations between three factors: the linguistic skills of deaf children aged five to ten, the extent to which their mothers use signs representing mental states, and the children's level of ToM. The mothers were asked to mark the signs they knew from a list of 25 signs representing mental states used by hearing parents in conversing with their children, among them think, know, guess and remember. Most of the parents (more than $80 \%$ ) reported that they used only very few of these signs (less than $30 \%$ ), and no difference was found between their children's level of ToM and that of children whose parents communicated using oral communication only. Children from both groups were marked by a three-year delay in their understanding of false beliefs. The researcher concluded that the parents in both groups made limited use of mental constructs in conversing with their children. Since the number of parents who did know more than a few mental signs was very small, it was impossible to find a correlation between high-level signing and level of ToM.

Moeller and Schick (2006) sought to further understand the relation between parent-child discourse and the mental understanding of deaf children, four to nine years old. The study's primary findings pointed to a strong correlation between the mothers' familiarity with mental signs and the extent to which they referred to mental states in conversing with their children. In addition, a correlation was found between mothers' level of mental-state discourse and their children's level of ToM, as measured by false belief tasks. In view of these findings, the researchers noted that parents of deaf children should be made aware of the importance of mental discourse with their children from an early age, as well as the importance of promoting mental discourse along with general linguistic abilities.

As pointed out above, deaf children of deaf parents exhibit a normal development of ToM. However, the deaf children who participated in these studies came from middle-to-high socioeconomic backgrounds. Previous studies have shown that socioeconomic status (SES) influences the linguistic input of the children (Hoff, 2003; Hoff \& Tian, 2005) and the development of ToM. The level of ToM among children of low SES is lower than that of children of higher SES (Holmes, Black \& Miller, 1996; Currenton \& Craig, 2011). Family attributes-among them mother's education and parents' income - are correlated with the content of parent-child discourse as well as with children's mental-state understanding (Curnton \& Craig, 2011; Cutting \& Dunn, 1999).

The deaf population in general is characterized by lower SES and lower level of education compared to the hearing society (Haran \& Strasberg 2012). Therefore, deaf children of deaf parents are, on the one hand, more likely than deaf children of hearing parents to be exposed to an accessible language from birth, but on the other hand are more likely to belong to a family of lower SES. Furthermore, most of the deaf parents themselves have hearing parents, and might have not been exposed to rich mental-state discourse in their childhood. How does this complex situation affect the mental discourse of the parents and the development of ToM in the children? 
To our knowledge, the mental-state discourse of deaf parents, either of mid-high or of low SES, with their deaf children has not yet been studied. Yet, in contrast to previous research that showed intact development among deaf signers from medium to high SES (e.g., Courtin, 2000), signers of low SES exhibit developmental delays that should be addressed. The need for a program became evident as result of delayed linguistic signing abilities and social competence of deaf Israeli toddlers from low SES, diagnosed by a parental report tool (Maital, Dromi, Sagi, $\&$ Bornstein, 2000). Whereas language and cognitive enrichment are central in their educational program in the Israeli educational system, promoting social understanding is less systematically addressed. Hence, there is a need to enhance the awareness of deaf parents to the importance of mental-state discourse in early childhood. It is on the basis of this background that the workshop described below was developed.

\section{Method: A Workshop to Enhance Deaf Parents' ToM Discourse}

Recognizing the centrality of parents' role in providing toddlers with intact social foundations, the current program aimed at guiding deaf parents how to enrich their natural discourse with their deaf children with developmentally appropriate references to mental states, i.e., ToM. Thus, the main purpose of this article is to describe the workshop and the principles underlying it, and to suggest how to apply previously accumulated theoretical and developmental findings regarding ToM development in guidance of deaf, low SES parents. To gain initial insights regarding the impact of such a program, we conducted an exploratory assessment that evaluated the change in parents' mental-state discourse with their children.

\subsection{Participants}

Participants were eight mothers of deaf toddlers who belonged to one daycare class and attended the daycare daily (ages 1:6-2:7 at the beginning of the school year). All eight mothers are deaf and use sign language as their main means of communication. Four mothers use Israeli Sign Language (ISL). The other four mothers are immigrants from the former Soviet Union countries and use Russian Sign Language (RSL). All participants belong to middle to low SES and have had 9-12 years of schooling. Their proficiency in written language (whether Hebrew or Russian) varied greatly. They attended all the sessions of the workshop.

\subsection{Setting}

The workshop took place in a center that provides clinical, educational and rehabilitation services for children with hearing loss and their families, in a large city in Israel. The center belongs to a national organization in charge of the education of children with hearing loss from birth to the age of six years. Children as young as 14 months may attend the center on a daily basis, as part of the preschool system in the center.

\subsection{Guiding Principles of the Workshop}

The workshop was based on a developmentally appropriate, ecologically valid and culturally sensitive approach. This approach is manifested in a number of guiding principles:

(a) Developmentally-appropriate preventive practice (Coople \& Bredekam, 2009). Because normal social and emotional development begins in infancy, parental guidance aiming to enhance the development of ToM should be instituted as early as possible, so as to lay the cognitive, social and emotional foundations underlying the development of ToM later on. The program was geared toward parents of young preschool children (ages 1:6 to $2: 7$ years old) and focused on those aspects of socio-emotional development appropriate for that age, e.g. desires and emotions (Astington \& Barriault, 2001, Ziv \& Frye, 2000).

(b) Ecologically valid, based on everyday activities (Sameroff \& Fiese, 2000). Mental discourse is an inseparable part of daily life. Hence, it is preferable to use ordinary routines for encouraging and enriching mental discourse with children. Meals and story reading were the two situations chosen in the present workshop.

(c) Interdisciplinary and family centered. Mental discourse should take place with many different individuals with whom the child interacts. Consequently, educational programs should emphasize interdisciplinary collaboration among professional staff members and parents (Ziv, Smadja \& Aram in press; Dinnebeil, Hole \& Rule, 1999). A comprehensive program was conducted, involving all the professionals in the preschool, as well as the parents. However, here we report only on one part of the program, namely the parental workshop sessions led by the children's daycare teacher.

(d) Culturally responsive. Deafness is not only a physiological characteristic; it is a social and cultural characteristic as well (Padden 1989). For many deaf and hard-of-hearing people, the cultural aspect of deafness is much more meaningful and important in the construction of their identity than the physiological characterization (see e.g., Bragg 2001, Leigh 2010). Many deaf and hard-of-hearing people regard themselves as members of the Deaf community, a community distinct from the surrounding hearing community, with its own language, values, shared history and attitudes (Padden \& Humphries 1988; Wilcox 1989, Lane et. al. 1996). 
In addition, deaf and hard-of hearing people come from different ethnic, socio-economical and linguistic backgrounds. They may also vary with respect to the mode of communication used (sign language, oral language or simultaneous communication). Any program should take these variables into consideration, and allow for flexibility in order to address the needs of each individual (Rivers, 2000). In the current program, the preschool teacher had a good command of Signed Hebrew, and various additional measures were taken to ensure that the program is sensitive to the cultural and socio-linguistic background of the parents. The mental signs questionnaire was translated to Israeli Sign Language (ISL), ISL-Hebrew interpreters were present in all the sessions, and materials and discussions were translated to Russian Sign Language and/or written Russian when needed.

\subsection{Workshop Design and Contents}

Parents met for six sessions during one school year, two hours long each. The sessions provided the theoretical basis of ToM development, as well as training in how to implement the theory in daily life, focusing on meal times and shared story reading. Importantly, the content of the sessions was closely linked to what the children were learning and experiencing in preschool. Thus, the parents were able to be partners in what was happening in school. Each session included an open discussion, during which parents described how they implemented what they had learned in their daily interactions with their children. Following is a short description of the meetings' contents:

Session one: theoretical background. Parents were first asked to complete two questionnaires -- the mental signs questionnaire (tool A) and the child description questionnaire (tool B). The session then introduced to the parents the basics of ToM and its development in children in general and in children with hearing loss in particular.

Sessions two and three: ToM during meals. Meals are an integral part of daily life in every home and every family as well as at preschool. They can therefore be used for emphasizing mental constructs in a natural manner. In the second session, parents were introduced to ways of integrating mental discourse during breakfast at preschool, and discussed possibilities for implementing a similar approach during meals at home. During the session, they watched a videotape of the children eating breakfast at preschool, showing the teacher explaining the mental constructs arising during the meal, how the children responded and how she mediated what occurred during breakfast. The parents expressed excitement in watching their children and paid attention to their children's behavior and linguistic abilities. "Did you see, my daughter said 'hummus'. At home she doesn't sign anything." "Way to go! They are imitating each other very nicely."

The third session was divided into two parts. The first part was devoted to sharing and listening to the parents' examples from family meals at home. The second part included participating in a simulated experiment, similar to the children's experience at preschool. The rationale was that such an experience helps parents better understand and internalize the theoretical elements of the program. Each parent had to choose between a savory biscuit and a sweet one, and each choice was recorded on the board using a picture of the chosen biscuit. Thus, a general picture of the choices and preferences of each participant emerged, similar to the picture created during the meeting with the children in preschool. This activity stimulated numerous responses referring to mental constructs. "It emphasizes my desires." "This shows more clearly what each person chose, because you can remember something you see." "You can also see who likes savory things and who likes sweets." "At home at supper I don't even ask my children what they want. I just put what they like on their plates." In addition, during this session parents were asked an open question regarding how they cope with a particular emotional situation at home (see research tool C).

Sessions four and five: mental discourse during story time. In the fourth session, the teacher familiarized the mothers with the books the children were exposed to at preschool and with the possibilities for mediation during the reading activity. Many of the parents were not familiar with the classic children's books. Therefore, the selected story (Eliezer and the Carrot by Levin Kipnis) was introduced to the parents. The story was presented twice, first to familiarize the parents with the book and then to explain the overt and covert possibilities offered by the story for mediating emotions and desires.

Session Five focused on emotions and desires in stories. The selected story was The Special Elephant by Paul Kor. The teacher succinctly outlined the story to one parent only, who in turn told the story to the rest of the group. The goal of this activity was to give the mothers a rendition of the story different from that of the teacher, which they had become accustomed to. After the story was read, the parents identified the mental constructs in the story and determined how they were expressed in pictures or in words/signs. As in earlier sessions, mediating the characters' emotions and desires was stressed, as were the reasons that led to their emotional responses and to solving the problems they encountered. In addition, the parents were given a demonstration of how to tie the events of the story to incidents in their children's lives through photographs of the children in a variety of emotional situations.

Session Six: concluding session. At the beginning of the session, the preschool teacher outlined the program content and activities. The mothers then completed the mental signs questionnaire (tool A) and the child description questionnaire (tool B). After that, the teacher facilitated a discussion during which the mothers gave 
examples of how they now respond to their children during their daily routine (tool C). Finally, the mothers summarized their views on the program and the teacher provided feedback on how the parents' relations with their children had changed during the year.

\subsection{Assessment Tools}

In order to gain insights regarding the impact of the program, three tools were used for assessing the changes in the parents' mental discourse. They were administered twice: Tools A and B were administered in the first and last sessions (October and June) and tool $\mathrm{C}$ was administered in the third and last sessions (February and June).

(a) Mental signs questionnaire. This tool is based on a questionnaire developed by Lundy (2002), in which parents are asked to indicate whether they use certain words with their child. The questionnaire contains 26 mental words, of four categories: desires, emotional mental states, activities expressing and reflecting emotions, and cognitive mental states (see Table 1), and ten distracters, denoting common daily activities, such as sleep, wash, swing, run. The purpose of the distracters was to avoid a situation in which parents sweepingly reported not using the mental-state signs being investigated, and to make them feel comfortable in reliably reporting the signs they do use and those they do not. In the current program the words in the questionnaire were rendered in signs. The preschool teacher photographed herself signing each of the signs, and these photographs comprised the list of words in the questionnaire (see Figure 1). When needed, signs were further translated into Russian Sign Language. Mental signs that mothers used were counted.

Table 1. Words used in the Mental Signs Questionnaire

\begin{tabular}{llll}
\hline Desires & Emotional mental states & Activities expressing emotions & Cognitive mental states \\
\hline choose & afraid & cry & Guess \\
like & angry & laugh & Know \\
don't like & excited & scream & don't know \\
want & Frightened & & Remember \\
don't want & Happy & & Think \\
& Jealous & & Understand \\
& Insulted & & \\
& Love & & \\
& Offended & \\
& Proud & & \\
& Sad & & \\
& Surprised & & \\
\hline
\end{tabular}

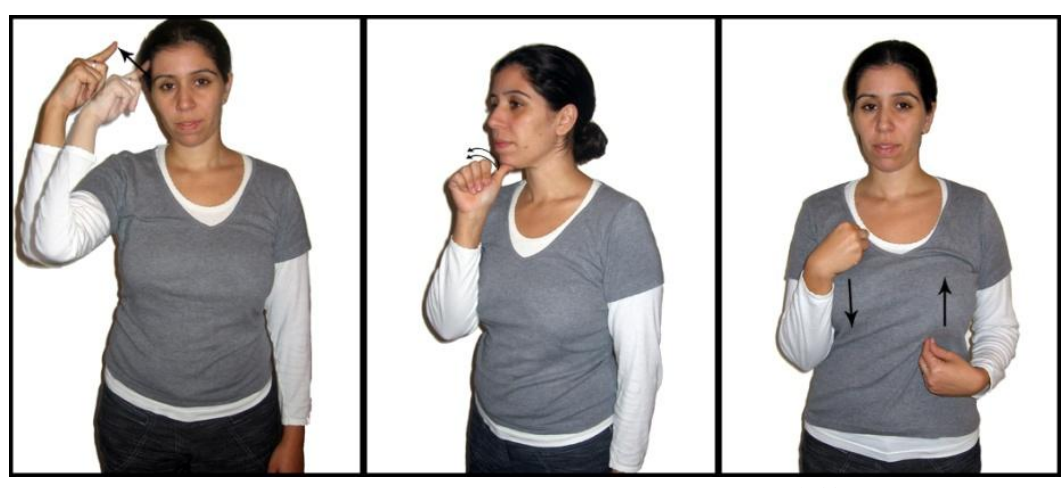

Know

Don't want

Offended

Figure 1. The Mental Signs Questionnaire translated into Israeli Sign Language: an example of three mental signs presented in Israeli Sign Language

(b) Child description questionnaire. Parents were asked to describe their child in three sentences or statements ("write three things describing your child"), based on Meins et al (2003).. The purpose of this tool was to see whether and how parents use mental constructs in describing their children. As not all parents in the group were proficient in reading and writing in Hebrew, the questionnaires were translated into Russian as well. Participants who had difficulties in filling out the questionnaires, whether in Hebrew or Russian, were assisted by the teacher or another parent. Participants' responses were scored and analyzed according to four measures: length of statements, use of mental words, linguistic structures and social constructs. 
(c) Open group discussion about mental states in the daily routine. An open questionnaire was developed for group discussion (Peterson \& Slaughter 2003), consisting of the following questions: 1. Have you and your child recently experienced a happy, frightening, sad or irritating incident, for example a birthday party, receiving a gift, fighting with siblings, a painful fall, an electrical outage, a cockroach in the kitchen? 2. Do you remember how your child responded? 3. Do you remember your own response? (Give an example). Parents could present their ideas in either Israeli Sign Language or Russian Sign Language. Mothers' responses were analyzed according to the following measures: references to the child's emotional state, references to the parent's emotional state, references to the emotional state of someone else involved, and explanations of the emotional state.

\section{Assessment Outcomes}

A major increase was found in all measures: frequency of use of mental signs (tool A), reference to mental states in describing the children (tool B), and references to mental terms in daily life (tool C). We present the assessment outcomes, accompanied by examples of mothers' reactions, in order to bring home the nature of the change they underwent in their mental discourse with their children.

Tool A, the mental sign questionnaire, revealed that the mean of mental words used by the participants increased over the year from 8.4 words per participant $(S D=4.6)$ in the first session to $17.9(S D=4.4)$ words per participant in the final session. That is, mothers' use of mental signs doubled from the first session to the last. Based on Wilcoxon Signed Ranks test, this difference was found to be significant $(\mathrm{Z}=-2.52, p=0.012)$. The use of words denoting non-mental daily activities (the distracters) also rose over the year, from a mean of 7.75 words per participant $(S D=3.57)$, to $10(100 \%)$. Importantly, an increase was found in every participant; that is, all mothers participating in the program used more mental signs by the last session.

When looking at the scores for each of the four categories of the mental words (the mean number of mothers using the words in each category), an increase was found in all categories (see Figure 2). The most noticeable increase was in words denoting cognitive mental states, which were reported to be hardly in use at the beginning of the year $(M=1.33, S D=1.9)$. In the last session, the majority of the mothers reported using the words in this category $(M=$ $5.00, S D=2.3$ ). In the category of activities reflecting emotions, all mothers except one used all three words by the final session. Furthermore, the use of the words denoting desires increased from a mean of $2.8(\mathrm{SD}=2.9)$ to a mean of 6.8 ( $\mathrm{SD}=1.6)$. Five mothers reported using all five words denoting desires by the final session. An examination of individual words reveals that words denoting desires and simple emotions (love, happy, sad, angry) were used by all mothers in the final session. The use of words denoting complex emotions, such as surprised, afraid, insulted, excited, also increased from a mean of $0.62(S D=1.06)$ to $3.25(S D=2.86)$.

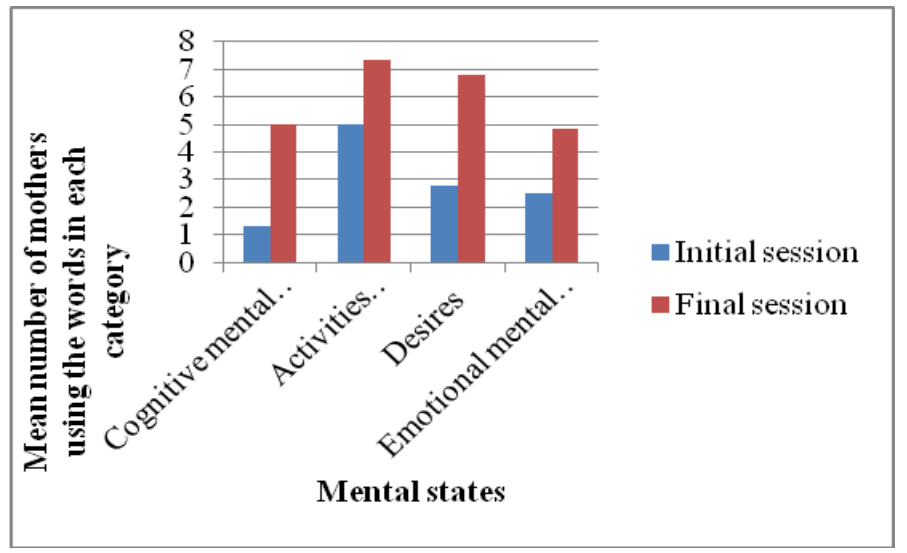

Figure 2. Mean use of mental words by mothers in four categories, before and after participation in the workshop

The child description questionnaire (Tool B) revealed increase in all assessed measures -- length of statements, use of mental words, linguistic structures and social constructs. First, the mothers' responses at the final session were longer $(M=5.4$ words per statement) and more detailed than those at the initial session $(M=3.22$ words per statement). A marked increase was also found in use of mental-state words, in both types and tokens. At the first session, the mothers' descriptions of the children contained 11 tokens of mental-state words and six types (satisfied, irritable, cry, love, study, spoiled). In the final session 22 tokens and ten types of mental words were found (know, love, responsible, concerned, listen, explain, want, don't want, stubborn, happy). While the early descriptions referred mainly to the children's behavior and simple emotions, the mothers' later descriptions referred additionally to the children's desires (examples: "doesn't want to go to sleep at night" "doesn't want mother to come to preschool"), as well as to knowing ("knows how to sit and listen" "knows when to talk and when to sign"). Additionally, an increase was found in the use of linguistic constructions involving complex sentences, i.e. verbs 
complemented by a subordinate clause (e.g., "explains what he wants") or infinitival forms (e.g., "likes to go to school"), from six clauses in the first session ( $28 \%$ of all statements) to 16 in the last (59\%). The mothers' responses in this tool at the first and final sessions are presented in the appendix.

Finally, there was an increase in the mothers' references to their child's social interactions. Initially, the proportion of the statements with reference to others was approximately $9 \%$, while over $90 \%$ referred to activities the child likes to do alone, e,g, "to play"; "music and dancing"; "she likes to be pretty". After participation in the workshop, $42 \%$ of mothers' statements referred to the children's desires in interacting and communicating with their friends and their family, for example: "He's a responsible and good brother; he likes his brother and plays with him." They also described the children's expanded ability to share their experiences with others: "He signs a lot and tells about things that happened at preschool." A binomial test revealed that the difference between the sessions in the reference to social interactions was significant $(\mathrm{p}<0.001)$. Moreover, prior to participating in the workshop, only two mothers described their children's social behavior. At the end of the year, all eight mothers did so.

In the open group discussion about mental states in their daily routine (tool C), initially five mothers actively participated in the discussion. At the end of the workshop all mothers participated and two provided more than one response to the trigger questions. The responses reflected a major change in mothers' responses to daily events. At the beginning, mothers' responses did not include any reference to the emotions of any of the people involved. They tended to overlook their child's emotion and their responses were behavioral, e.g., they pulled the child away from a dog, or instructed the child to stop crying. At the end of the workshop, 15 responses contained references to mental states of the child, the mother or some other person, describing happiness, jealousy, sadness and excitement. Mothers indicated that they became more aware of the importance of mediation, e,g," "Now when Daniel and Yuval fight, I separate them immediately and tell each one what he feels." The following example demonstrates mediation referring to desire as well as to cognitive mental states (know, think). "Daniel knows that we're going to the mall. He can choose one item. I always tell him to think it over carefully and then to tell me what he wants, just one thing. I let him choose. Just like Lucy [the teacher] said, he can't get everything he wants."

Furthermore, at the beginning of the year the mothers made no reference to the emotional states of other people involved in an incident, neither themselves nor others such as brothers and sisters, friends and other family members. At the end of the workshop, all mothers referred to others' mental state. Let us compare, for example, the following two responses exemplifying the change in how parents mediate when referring to their feelings. "When we went to the playground on Saturday we saw a very big dog and I was afraid. Shir wanted to pet it, but I pulled him away and we left" (January). Compare this to the following: "I wasn't feeling well during the last days of my pregnancy, and I was angry about everything. My husband told Liat, 'Mommy is sick, her tummy hurts.' She was so sweet. She came over to me and signed, 'Do you want a Band-Aid?' I explained to her that my tummy hurts and I'm uncomfortable right now" (June). In the first statement, the mother reports her own emotional state, but does not discuss it with her son. Her response to the incident is behavioral only — she pulled the boy to get him away from the scary dog. The second response refers to and expresses the mother's emotional state and provides the daughter with a verbal explanation of this emotional state.

The following examples further demonstrate how a mother referred at the end of the year to the emotions of others, as well as to the reasons that underlie these emotional reactions: "It was Yoav's mother's birthday, and we blew up balloons. Daniel and Yuval were so happy, and Yuval made her a card at school and read it, and she actually cried. I explained to Daniel that she cried because it was her birthday and she was very excited." Reference is made to Yoav's mother's emotional state, as well as to Daniel's and Yuval's feelings. In addition, Daniel's mother explained why Yoav's mother cried. Her explanation makes a direct connection between external behavior and emotional state, and points to the causal relation between emotion and behavior.

Furthermore, the mothers started using words denoting complex mental states (insulted, jealous), as in the following example, in which the mother explains to her son what another girl is feeling, and why she feels that way. "Thursday was Ofir's uncle's birthday, and we went to Beer Sheva. All the cousins gave him presents and were happy, and my sister's daughter started to cry. Ofir asked me what had happened. I told him that she wanted a birthday party too, and Ofir signed to me, was she insulted? I told him she was jealous, just like he feels jealous when Sharon gets something and he doesn't. I reminded him that the other day I gave Sharon a piece of candy, but he didn't get one because he misbehaved."

\section{Discussion}

Recognizing the importance of ToM for children's social development, the workshop aimed at providing deaf parents with guidelines for enriching their mental-state discourse with their children. Consistent with this goal, following their participation, the mothers made more references to mental terms, both in the discourse with their children and in the descriptions of their children's behavior and personality. First, the mental-state vocabulary used 
by the mothers in conversing with their children became richer, as indicated by the answers to the mental signs questionnaire. At the beginning of the year, the mothers primarily used words indicating desires and basic emotions. By the end of the year, they were also using words indicating preference (like and don't like) and those indicating more complex emotions, such as surprised, excited and insulted. At the end of the year, the mothers also began using cognitive mental verbs, such as know.

Use of verbs and adjectives referring to mental states is pivotal in promoting mental-state understanding among children (Adrian et al., 2005, Ruffman et al., 2002). A vocabulary abundant in mental-state terms facilitates exposure to a wealth of mental aspects characterizing human behavior and interactions. The findings indicate that the mothers increased their awareness of a wide variety of mental-state terms and were able to implement this awareness in conversing with their children.

The change in the mothers' mental-state awareness also emerged in their description of their child (tool B). Initially, a single mental-state word - like or love - was widely used, in most cases describing things the child liked to do: "He only likes to eat," "She likes to be pretty," "She loves Mommy." Only one mother used the word want. In contrast, at the end of the workshop, mothers referred to a broader range of mental-state characteristics of their children, describing not only what the children like but also what they want and what they know: "She's stubborn and always wants to be in control"; "She knows when to sign and when to speak." Furthermore, the descriptions at the end of the year referred to their child's relations with other children and with adults, playing with other children, expressions of responsibility and concern for a younger sibling, sharing experiences of another child, as well as insisting on own desires in conflicts with another child; such references did not appear at all earlier.

The open discussions in tool $\mathrm{C}$ also revealed an increase in the number, variety and complexity of mental states referred to by the mothers. By the end of the workshop these discussions included words like jealous and insulted. The short, behaviorally-focused descriptions of the beginning of the year made way to much more detailed responses, mediating to the child his/her own emotions, as well as those of other children and adults involved in the interaction: "I told him that she was jealous, just like he [the child] feels jealous when Sharon gets something and he doesn't".

These changes in how the mothers described their children reflect their increased awareness of- and sensitivity to their children's mental-state attributes. Longitudinal studies of hearing children and their mothers noted that this awareness and sensitivity form the basis for developing children's mental understanding, showing that the mothers' mental awareness and sensitivity was closely related to the children's level of ToM (Meins et al., 2003).

Previous studies noted that parental mediation, emphasizing different points of view and emotional states of others in natural contexts, is of major importance for the development of mental-state understanding in children (Harris, 2005) and that this mediation is lacking in the experience of children with hearing loss (Peterson \& Slaughter, 2006). The current study indicates that deaf parents of deaf children from low SES can be helped to enrich their mental mediation when conversing with their children and thus to create better environmental conditions for developing ToM.

The mothers' discourse changed in terms of a number of linguistic measures as well: enriched vocabulary and an increase in the length and complexity of statements. The changes in the linguistic characteristics of parental discourse took place even though the program did not directly emphasize the importance of purely linguistic structures. However, studies have pointed to the close reciprocal relations between linguistic knowledge and ToM (De Villiers, 2006), as well as to the centrality of language in conveying mental content (Astington \& Baird, 2005). As explained above, a rich mental vocabulary forms the basis for discourse that is not limited to concrete concepts. Moreover, complex syntactic structures, and in particular subordinate complement clauses of mental verbs, are an important means for describing complex mental states, among them false beliefs (De Villiers, 2006). Our findings show that a program focusing on enriching parental discourse and mental-state mediation also naturally leads to changes in the linguistic nature of the parental input. Consequently, parental discourse is enriched with respect to both mental states and linguistic constructs, and the children are exposed to language that is richer and more complex in content and in structure.

A central element in the program was the cultural sensitivity towards the parents and children who participated in it. Cultural sensitivity has gained growing recognition in the realm of education (Rivers, 2000; Rogoff, 2003). The daycare teacher was familiar with the parents and with the Israeli Deaf community and used specific measures to create an open and cooperative atmosphere in which parents could comfortably relate to the information provided to them and openly and easily share their experiences. The following reactions of the mothers, when realizing that the mental signs questionnaire (tool A) was translated into sign language, are clear indications that these measures were successful: "Wow, this is the first time I've seen a questionnaire that uses signs," "Filling this out is fun, easy and doesn't require any effort," "You really understand deaf people."

Importantly, the workshop addressed the characteristics of signing families of middle to low SES. Previous studies focused on signing deaf children of deaf parents from middle-high SES. These studies found that the children were 
not delayed in their TOM development, due to rich linguistic and social interactions they experienced (Courtin, 2000; Courtin \& Melot, 2005; Schick, De-Villiers, De-Villiers \& Hoffmeister, 2007). However, studies on hearing children of low SES pointed to a significant discrepancy between them and children whose SES is higher on a variety of linguistic and cognitive abilities, among them ToM (Curenton \& Craig, 2011; Cutting \& Dunn, 1999; Holmes et al., 1966). In our study, the mothers were deaf and from mid-low SES. Their responses to tools A and B at the first session indicate that prior to the workshop their conversations with their children were characterized by limited reference to ToM aspects. In that, they resemble hearing mothers from low SES (Levin \& Aram, 2010). The high rate of attendance throughout the workshop, the change in mothers' discourse as indicated by their responses to the same tools at the end of the workshop, and their positive reactions regarding their mental discourse and mediation with their children, are all evidence that the measures taken to meet their needs were successful. The mothers expressed their enhanced feelings of capability and excitement in view of the changes they observed in their children's abilities and in their own abilities to react to their children's sayings.

Despite the seemingly significant impact of the workshop and its sensitivity towards the mothers who participated, a possible explanation for the changes in the mothers' discourse is the development and maturation of the children. Possibly, mothers increased their use of mental-state signs as children became more communicative and engaged with other children in the daycare settings. In the current study, constructing a relevant control group was not feasible. Although this may be considered a limitation of the current study, it is important to note that the special characteristics of the group of parents that were involved in the program made it impossible to construct an informative control group. All the mothers in the study were deaf, used sign language as their main means for communicating with their children and their children went to the same class in the preschool. Therefore, it was possible for the teacher, who was knowledgeable in the topic of ToM development, to work with the parents as a group, and to connect the activities in the workshop to the daily routine in the preschool. In no other preschool class for children with hearing loss in the country are all the parents deaf. Any control group would differ from the study group in various aspects (e.g. the hearing status of the parents, their SES, whether or not their children go to the same preschool class, the teacher's knowledge and practice), making the comparison between the groups invalid and uninformative. Importantly, however, mothers' spontaneous insights provide preliminary support for a significant change in their behavior, beyond adaptation to children's growing abilities. For example, one mother explicitly noted that following the workshop, she talks differently not only with her deaf toddler but also with his older deaf sister and even with her husband. Another mother commented: "When Daniel and Sharon fall down, I explain what happened and tell them to be careful. That's what Lucy [the teacher] told us to do. So that's what I do." Other participants agreed and added that they became more aware of their own feelings and desires and understand that it is important to talk about them.

\section{Conclusions}

Studies point to the importance of parents as the primary agents in mediating the social world for their children and indicate that this mediation should be rich and varied, both mentally and linguistically (e.g., Aram, Fine \& Ziv, 2013). Moreover, children should be exposed to diverse social experiences and introduced to a variety of points of view (Ziv, Smadja \& Aram, 2013). The challenge is to create a program to enhance such mediation and incorporate it in every-day activities and discourse. In this paper we describe a program that aims to do that. Its main goals were to make parents aware of the importance of mental-state discourse and mediation when communicating with their children, and to empower them as main agents carrying out this undertaking by suggesting ways to incorporate mental-state discourse in their family's daily routine. The assessment tools and the conversations of the school teacher with the parents indicate that the endeavor was successful. The mothers who participated in the current workshop indeed enriched their discourse and mediation with respect to the main factors that the literature describes as contributing to the development of ToM among young children. Note that the program did not train the parents in how to answer the questions on the testing tools, but rather used these tools to assess their spontaneous interactions with their children in numerous contexts.

Due to the close association between the social-emotional and linguistic fields, educational programs should integrate both components so that development in one area will support development in the other, and vice versa. Together they will help children with hearing loss become better integrated into the "mental community" (Nelson, 2005), enabling them to experience meaningful and diverse social ties.

The current workshop was intended for parents of very young deaf children, from low SES, based on recognition of the importance of creating a foundation for social understanding among children at risk in the early stages of development. It is important in such programs to sensitively address the characterizations and needs of different populations with hearing loss, including native signers who exhibit developmental delays. More research is needed in order to determine the most beneficial ways to promote ToM in children with hearing loss at an early stage. 
Additionally, continuation programs should be designed for older children and their parents to enhance their social understanding and enable them to implement it in multiple situations and interactions.

\section{Acknowledgements}

We thank Drorit Ben Itschak for her enlightening comments on earlier versions of the manuscript and Keren Banai for her help with the statistics. We express deep appreciation to all the parents and children who participated in the program.

\section{References}

Adrián, J. E., Clemente, R. A., \& Villanueva, L. (2007). Mother's use of cognitive state verbs in picture-book reading and the development of children's understanding of mind: A longitudinal study. Child Development, 78, 1052-1067. http://dx.doi.org/10.1111/j.1467-8624.2007.01052.x

Adrián, J. E., Clemente, R. A., Villanueva, L., \& Rieffe, C. (2005). Parent-child picture-book reading, mother's mental state language and children's theory of mind. Journal of Child Language, 32, 673-686. http://dx.doi.org/10.1017/S0305000905006963.

Aram, D., Fine, Y., \& Ziv, M. (2013). Promoting children's social cognition during shared book reading with preschool children, Early Childhood research Quarterly, 28, 111-122. http://dx.doi.org/10.1016/j.ecresq.2012.03.005

Astington, J. W., \& Baird, J. A. (2005). Why language matters? In: J.W. Astington, \& J.A Baird (Eds.). Why Language Matters for Theory of Mind? (pp. 3-25). Oxford University Press.

Astington, J. W., \& Barriault, T. (2001). Children's theory of mind: How young children come to understand that people have thoughts and feelings. Infants and Young Children, 13, 3, 1-12.

Bernard, S. M., \& Deleau, M. (2007). Conversational perspective taking and false belief attribution: A longitudinal study. Journal of Developmental Psychology, 25, 443-460. http://dx.doi.org/10.1348/026151006X171451

Bragg, L. (2001). Deaf world. New York and London: New York University Press.

Calderon, R., \& Greenberg, M. T. (2003). Social and emotional development of deaf children: Family, school and program effects. In M. Marschark \& P. E. Spencer (Eds.). Oxford Handbook of Deaf Studies, Language, And Education. (pp. 177-189). Oxford University Press.

Coople, C., \& Bredenkamp, S. (Eds.). (2009). Developmentally Appropriate Practice in Early Childhood Programs. National Association for the Education of Young Children. Washington, DC, USA.

Courtin, C. (2000). The impact of sign language on the cognitive development of deaf children: the case of theories of mind, Journal of Deaf Studies and Deaf Education, 266-276. http://dx.doi.org/10.1093/deafed/5.3.266

Courtin, C. \& Melot, A.M. (2005). Metacognitive development of deaf children: Lessons from the appearance-reality and false belief tasks, Developmental Science, 8(1), 16-25. http://dx.doi.org/10.1111/j.1467-7687.2005.00389.x

Curenton, S. M., \& Craig, M. J. (2011). Shared-reading versus oral storytelling: Associations with preschoolers' prosocial skills and problem behaviors. Early Child Development and Care, 181(1), 123-146. http://dx.doi.org/10.1080/03004430903292208

Cutting, A.L., \& Dunn, J. (1999). Theory of mind, emotion understanding, language and family background: Individual differences and interrelations. Child Development, 70, 853-865. http://dx.doi.org/10.1111/1467-8624.00061

De Villiers, J. V. (2006). Can language acquisition give children a point of view? In: J.W. Astington, \& J.A Baird (Eds.). Why Language Matters for Theory of Mind? (pp. 186-219). Oxford University Press.

Dinnebeil, L., Hole, L., \& Rule, S. (1999). Early intervention program practices that support collaboration, Topics in Early Childhood Special Education, 19(14), 225-235.

Flavell, J. H., \& Miller, P. (2000). Social cognition. In: D. Kuhn, \& R.S. Siegler (Eds.). Handbook of Child Psychology. Volume 2: Cognition, Perception and Language (pp. 851-898). John Wiley \& Sons, Inc.

Gray, C. D, Hosie, J. A, Russell, P. A., Scott, C., \& Hunter, N. (2007). Attribution of emotion to story characters by severely and profoundly deaf children. Jornal of Developmental and Physical Disabilities, 19, 145- 159. http://dx.doi.org/10.1007/s10882-006-9029-1

Haran, D., \& Strasberg, N. (2012). People with Hearing Disability: Occurrence and Characteristics. Myers, JDC, Brookdale Institute [In Hebrew]. 
Harris, P. L. (2005). Conversation, Pretence and Theory of Mind. In: J.W. Astington, \& J.A Baird (Eds.). Why Language Matters for Theory of Mind? (pp. 70-83). Oxford University Press.

Hoff, E. (2003). The specificity of environmental influence: Socioeconomic status affects early vocabulary development via maternal speech. Child Development, 74, 1368-1378. http://dx.doi.org/10.1111/1467-8624.00612

Hoff, E., \& Tian, C. (2005). Socioeconomic status and cultural influences on language. Journal of Communication Disorders, 38, 271-278. http://dx.doi.org/10.1016/j.jcomdis.2005.02.003

Holmes, H. A., Black, C., \& Miller, S. A. (1996). A cross-task comparison of false belief understanding in Head-Start population. Journal of Experimental Child Psychology, 63, 263-285. http://dx.doi.org/10.1006/jecp.1996.0050

Jeanes, R. C., Nienhuys, T. G., \& Rickards, F. W. (2000). The pragmatic skills of profoundly deaf children. Journal of Deaf Studies and Deaf Education, 5(3), 237-247. http://dx.doi.org/10.1093/deafed/5.3.237.

Kipnis, L. Eliezer and the Carrot. Sefer La-Kol publishers [in Hebrew].

Kor, P. The Special Elephant. Or Yehuda: Dvir Publishers [in Hebrew].

Lane, H., Hoffmeister, R., \& Bahan, B. (1996). A Journey into the Deaf-World. San Diego, California: Dawn Sign Press.

Leigh, I. W. (2010). Reflections on identity. In Marschark, M. \& Spencer, P. (Eds.) (2010a). Oxford Handbook of Deaf Studies, Language, and Education, Volume 2. Oxford: Oxford University Press.

Levin, I., \& Aram, D. (2010). Mother-child joint writing and storybook reading and their effects on kindergartners' literacy, Reading and Writing, 25(1), 217-249. http://dx.doi.org/10.1007/s11145-010-9254-y

Liu, D., Wellman, H. M., Tardif, T., \& Sabbagh, M. A. (2008). Theory-of-mind development in Chinese children: A meta-analysis of false belief understanding across cultures and languages. Developmental Psychology, 44, 523-531. http://dx.doi.org/10.1037/0012-1649.44.2.523

Lundy, J. E. B. (2002). Age and language skills of deaf children in relation to theory of mind development. Journal of Deaf Studies and Deaf Education, 7, 41-56. http://dx.doi.org/10.1093/deafed/7.1.41

Macaulay, C. E., \& Ford, R. M. (2006). Language and theory of mind development in prelingually deafened children with cochlear implants: A preliminary investigation. Cochlear Implants International, 7(1), 1-14. http://dx.doi.org/10.1002/cii.22.

Maital, S. L., Dromi, E., Sagi, A., \& Bornstein, M. H. (2000) The Hebrew Communicative Development Inventory: Language specific properties and cross-linguistic generalizations. Journal of Child Language, 27, 43-67.

Meins, E., Fernyhough, C., Wainwright, R., Clark-Carther, D., Das Gupta, M., Fradley, E., \& Tuckey, M. (2003). Pathways to understanding the mind: Construct validity and predictive validity of maternal mind-mindedeness. Child Development, 74, 1194-1211.

Meir, I. (2007). The right for a mother tongue. Speech and Hearing 28, 2006-2007, $33-46$ [In Hebrew].

Mitchell, R. E., \& Karchmer, M. A. (2004). Chasing the mythical ten percent: Parental hearing status of Deaf and Hard of Hearing students in the United States. Sign Language Studies, 4(2), 138-163.

Moeller, M. P., \& Schick, B. (2006). Relations between maternal input and theory of mind understanding in deaf children. Child Development, 77, 751-766. http://dx.doi.org/10.1111/j.1467-8624.2006.00901.x

Nelson, K. (2005). Language pathways into the community of minds. In: J.W. Astington, \& J.A Baird (Eds.). Why Language Matters for Theory Of Mind? (pp. 26-49). Oxford University Press.

Padden, C. (1989). The Deaf community and the culture of Deaf people. In Wilcox, S. (ed.) (1989). American Deaf Culture. Silver Spring MD: Linstok Press, 1-16.

Padden, C., \& Humphries, T. (1988). Deaf in America: Voices from a Culture. Cambridge, Ma.: Harvard University Press.

Padden, C., \& Humphries, T. (2005). Inside Deaf Culture. Cambridge, Mass.: Harvard University Press.

Peters, S., Remmel, E., \& Richards, D. (2009). Language, mental state vocabulary, and false belief understanding in children with cochlear implants. Language, Speech and Hearing Services in Schools, 40, 245-255. http://dx.doi.org/10.1044/0161-1461.

Peterson, C. C. (2004). Theory of mind development in oral deaf children with cochlear implants or conventional hearing aids. Journal of Child Psychology and Psychiatry, 45, 1096-1106. 
http://dx.doi.org/10.1111/j.1469-7610.2004.t01-1-00302.x

Peterson, C. C., \& Siegal, M. (1995). Deafness, conversation and theory of mind. Journal of Child Psychology, 36, 459-479. http://dx.doi.org/10.1111/j.1469-7610.1995.tb01303.x

Peterson, C. C., \& Siegal, M. (2000). Insights into Theory of Mind from deafness and autism. Mind and Language, 15, 123-14. http://dx.doi.org/10.1111/1468-0017.00126

Peterson, C., \& Slaughter, V. (2003). Opening windows into the mind: mothers' preferences for mental state explanations and children's theory of mind. Cognitive Development, 18, 399-429. http://dx.doi.org/10.1016/S0885-2014(03)00041-8

Peterson, C. C., \& Slaughter, V. (2006).Telling the story of theory of mind: deaf and hearing children's narratives and mental state understanding. British Journal of Developmental Psychology, 24, 151-179. http://dx.doi.org/10.1348/026151005X60022

Peterson, C. C., Wellman, H. M., \& Slaughter, V. (2012). The mind behind the message: Advancing theory-of-mind scales for typically developing children and those with deafness, autism and Asperger syndrome. Child Development, 83, 469-485. http://dx.doi.org/10.1111/j.1467-8624.2011.01728.x

Peterson, C. C., \& Wellman, H. M. (2009). From fancy to reason: Scaling deaf and hearing children's understanding of theory-of-mind and pretence. British Journal of Developmental Psychology, 27, 297-310. http://dx.doi.org/10.1348/026151008X299728

Peterson, C. C., Wellman, H., \& Liu, D. (2005). Steps in theory of mind development for children with deafness or autism. Child Development, 76, 502-518. http://dx.doi.org/10.1111/j.1467-8624.2005.00859.x

Preisler, G., Tvingstedt, A. L., \& Ahlstrom, M. (2002). A psychosocial follow-up of deaf preschool children using cochlear implants. Childcare, Health \& Development, 28(5), 403-418. http://dx.doi.org/10.1046/j.1365-2214.2002.00291.x

Repacholi, B. M., \& Gopnik, A. (1997). Early reasoning about desires: Evidence from 14- and 18- month olds. Developmental Psychology, 33, 12-21. http://dx.doi.org/10.1037/0012-1649.33.1.12

Remmel, E., \& Peters, K. (2008). Theory of mind and language in children with cochlear implants. Journal of Deaf Studies and Deaf Education, 14, 218-236. http://dx.doi.org/10.1093/deafed/enn036.

Rivers, K. O. (2000). Working with caregivers of infants and toddlers with special needs from culturally and linguistically diverse backgrounds. Infant-Toddler Intervention: The Transdisciplinary Journal, 10(2), 61-72.

Rogoff, B. (2003). The Cultural Nature of Human Development. New York: Oxford University Press.

Ruffman, T., Slade, L. \& Crowe, E. (2002). The relation between children's and mothers' mental state language $\begin{array}{lllll}\text { and Theory-of-mind understanding. Child Development, 73, } & \text { 751. }\end{array}$ http://dx.doi.org/10.1111/1467-8624.00435.

Sameroff, A. J., \& Fiese, B. H. (2000). Transactional regulation: The development of ecology of early intervention. In J.P. Shonkoff \& J.J. Meisels (Eds.), Handbook of Early Childhood Intervention (pp. 135-159). NY, USA: Cambridge University Press.

Schick, B., De-Villiers, P., De-villiers, J., \& Hoffmeister, R. (2007). Language and theory of mind: a study of deaf children. Child Development, 78(2), 376-396. http://dx.doi.org/10.1111/j.1467-8624.2007.01004.x

Taumoepeau, M., \& Ruffman, T. (2008). Stepping stones to others' minds: Maternal talk relates to child mental state language and emotion understanding. Child Development, 79(2), 284-302. http://dx.doi.org/10.1111/j.1467-8624.2007.01126.x

Terwogt, M. M., \& Rieffe, C. (2004). Deaf children's use of beliefs and desires in negotiations. Journal of Deaf Studies and Deaf Education, 9, 27-38. http://dx.doi.org/10.1093/deafed/enh013

Tomasello, M., Carpenter, M., Call, J. Behne, T., \& Moll, H. (2005). Understanding and sharing intentions: The origins of cultural cognition. Behavioral and Brain Sciences, 28, http://dx.doi.org/10.1017/S0140525X05380125

Wellman, H. M., Phillips, A. T., \& Rodriguez, T. (2000). Young Children's Understanding of Perception, Desire and emotion. Child Development, 71, 895- 912. http://dx.doi.org/10.1111/1467-8624.00198

Wellman, H. M, Cross, D., \& Watson, J. (2001). Meta-analysis of theory of mind development: The truth about false belief. Child Development, 72, 655-684. http://dx.doi.org/10.1111/1467-8624.00304 
Wilcox, S. (ed.) (1989). American Deaf Culture. Silver Spring MD: Linstok Press.

Wimmer, H. M., \& Perner, J. (1983). Beliefs about beliefs: Representation and constraining function of wrong beliefs in young children's understanding of deception. Cognition, 13, 103-128. http://dx.doi.org/10.1016/0010-0277(83)90004-5

Woolfe, T., Want, S. C., \& Siegal, M. (2002). Signposts to development: Theory of mind in deaf children. Child Development, 73(3), 768-778. http://dx.doi.org/10.1111/1467-8624.00437.

Zahn-Waxler, C., Radke-Yarrow, M., \& Wagner, E. (1992). Development of concern for others, Developmental Psychology, 28,_126-136. http://dx.doi.org/10.1037/0012-1649.28.1.126

Ziv, M., \& Frye, D. (2002). The relation between desire and false belief in children's theory of mind: No satisfaction? Developmental Psychology, 39(5), 859-876.

Ziv, M., Smadja, M., \& Aram, D. (2013). Mother-child mental-state discourse during shared book reading with preschool children, Early Childhood Research Quarterly, 28, 177-186. http://dx.doi.org/10.1016/j.ecresq.2012.05.005

Ziv, M., Smadja, M., \& Aram, D. (in press). Mothers' and Teachers' Mental-State Discourse with Preschoolers During Storybook Reading. Journal of Cognitive Education and Psychology.

Appendix: Mothers' responses in the child description questionnaire (Tool B)

\begin{tabular}{|c|c|c|}
\hline Mother & Initial session & Final session \\
\hline 1 & $\begin{array}{l}\text { Sings in sign language } \\
\text { Meets her friends } \\
\text { What's important is that she will be content } \\
\text { and won't be upset and cry }\end{array}$ & $\begin{array}{l}\text { Knows how to sit and listen } \\
\text { Likes to be in school and play with her friends } \\
\text { Can be the one in charge and responsible for peeing }\end{array}$ \\
\hline 2 & $\begin{array}{l}\text { Plays (especially Spiderman) } \\
\text { Be in charge and help with cleaning up } \\
\text { Hugs and kisses }\end{array}$ & $\begin{array}{l}\text { Likes Lucy and the kindergarten } \\
\text { Responsible and a good brother, takes care of and plays } \\
\text { with S. } \\
\text { Signs a lot and tells things that happened in school }\end{array}$ \\
\hline 3 & $\begin{array}{l}\text { Likes to listen } \\
\text { Goes on outings, plays, very independent } \\
\text { Music and dances }\end{array}$ & $\begin{array}{l}\text { He grew up so much, he talks, signs, sings, I can't believe it } \\
\text { Likes to go to the swimming pool } \\
\text { Explains what he wants and doesn't cry right away }\end{array}$ \\
\hline 4 & $\begin{array}{l}\text { Likes to listen to stories } \\
\text { Wants to learn more words in sign language } \\
\text { Plays with kids }\end{array}$ & $\begin{array}{l}\text { Signs many words in sign language } \\
\text { Likes to be with Dad and go on outings } \\
\text { Doesn't want to go to sleep at night, only TV }\end{array}$ \\
\hline 5 & $\begin{array}{l}\text { Likes red and pink } \\
\text { Songs and music } \\
\text { Likes to be pretty }\end{array}$ & $\begin{array}{l}\text { Sweet girl, like pretty clothes } \\
\text { Talks a lot, sings } \\
\text { She's stubborn, and wants to be in control all the time }\end{array}$ \\
\hline 6 & Likes only to eat & $\begin{array}{l}\text { Talks a lot and signs } \\
\text { Knows when to talk and when to sign } \\
\text { Plays very nicely with his friends }\end{array}$ \\
\hline 7 & $\begin{array}{l}\text { She loves Mommy } \\
\text { Spoiled } \\
\text { A gentle girl }\end{array}$ & $\begin{array}{l}\text { Signs many words and says what she wants } \\
\text { Doesn't want mother to come to preschool } \\
\text { Beats other kids and fight over her belongings }\end{array}$ \\
\hline 8 & $\begin{array}{l}\text { Doesn't know school } \\
\text { Doesn't play } \\
\text { No signs }\end{array}$ & $\begin{array}{l}\text { Has signs } \\
\text { Happy and likes to go to school } \\
\text { Likes to play with dolls and in the kitchen } \\
\text { Talks to herself a lot }\end{array}$ \\
\hline
\end{tabular}

\section{$($ (c) $)$ EY}

This work is licensed under a Creative Commons Attribution 3.0 License. 